\title{
TRANSPLANTATION OF CRYOPRESERVED CARDIOMYOCYTES
}

Hiroki Yokomuro, MD

Ren-Ke Li, MD, PhD

Donald A. G. Mickle, MD

Richard D. Weisel, MD

Subodh Verma, MD, PhD

Terrence M. Yau, MD, MSc
Background: The present study examined the survival and rate of contraction of (1) cardiomyocytes cultured from cryopreserved fetal rat myocardium and (2) cryopreserved cultured cardiomyocytes. In addition, the effects of transplantation of cryopreserved fetal cardiomyocytes were evaluated.

Methods: Segments of fetal rat myocardial tissue $\left(0.2,2.0\right.$, and $6.0 \mathrm{~mm}^{3}$ mince size) and cultured cardiomyocytes were cryopreserved in liquid nitrogen for 1, 2, and 4 weeks. After cryopreservation, the tissue samples and cultured cardiomyocytes were thawed at $37^{\circ} \mathrm{C}$ and cultured, and cell proliferation and rate of contraction were determined. Cultured cryopreserved $(n=5)$ and noncryopreserved (control, $\mathrm{n}=5$ ) fetal cardiomyocytes were transplanted into the subcutaneous tissue and into a transmural left ventricular free wall scar of Sprague-Dawley rats $(n=3)$. The survival and rate of contraction of these transplanted cells were also examined.

Results: Cryopreservation of cultured fetal cardiomyocytes resulted in viable and functional cardiomyocytes although the cell number and percentage of beating cells were diminished. Survival of cardiomyocytes isolated from cryopreserved fetal myocardium was a function of tissue size before cryopreservation; the lowest survival was recorded in tissues with the largest mince size $\left(6.0 \mathrm{~mm}^{3}\right)$. The subcutaneous transplants contracted spontaneously and regularly with an idioventricular rhythm. In addition, the transplanted cardiomyocytes were elongated and formed a myocardium-like pattern with blood vessels present within the contractile tissue. In the transmural left ventricular scar, both control and experimental fetal cardiomyocyte transplants formed myocardium-like tissue.

Conclusions: The present study uncovers the following key observations: (1) cryopreservation of fetal cardiomyocytes and cardiomyocytes isolated from cryopreserved myocardial tissue results in viable and functional cells, (2) cryopreserved fetal cardiomyocytes can be successfully transplanted into subcutaneous and myocardial scar tissue, and (3) improvements in cryopreservation techniques are required to augment the rates of cardiomyocyte survival observed in the study. (J Thorac Cardiovasc Surg 2001;121:98-107)
$\mathrm{M}$ yocyte implantation into myocardial tissue is the subject of increasing attention. In experimental models of left ventricular cryonecrosis, skeletal muscle myoblast transplantation has been demonstrated to improve myocardial function. ${ }^{1}$ In addition, results

From the Division of Cardiovascular Surgery, Department of Laboratory Medicine and Pathobiology, Toronto General Hospital, University of Toronto, Toronto, Ontario, Canada.

R.K.L. is a Research Scholar of the Heart and Stroke Foundation of Canada. S.V. is a Fellow of the Medical Research Council of Canada. This research was supported by a grant from the Medical Research Council of Canada (grant No. MT-13665) to R.K.L.

Read at the Eightieth Annual Meeting of The American Association for Thoracic Surgery, Toronto, Ontario, Canada, April 30-May 3, 2000 . from our research group have indicated that transplantation of freshly cultured fetal rat cardiomyocytes $^{2}$ and autologous heart cells ${ }^{3}$ into myocardial scar tissue limited scar expansion and improved cardiac function.

Received for publication May 4, 2000; revisions requested June 12, 2000; revisions received July 26, 2000; accepted for publication Sept 3, 2000.

Address for reprints: Ren-Ke Li, MD, PhD, Toronto General Hospital, CCRW 1-815, 200 Elizabeth St, Toronto, Ontario, Canada, M5G 2C4 (E-mail: RenKe.Li@uhn.on.ca).

Copyright (C) 2001 by The American Association for Thoracic Surgery

0022-5223/2001 $\$ 35.00+0 \quad \mathbf{1 2 / 6 / 1 1 1 4 1 8}$

doi: $10.1067 / \mathrm{mtc} .2001 .111418$ 


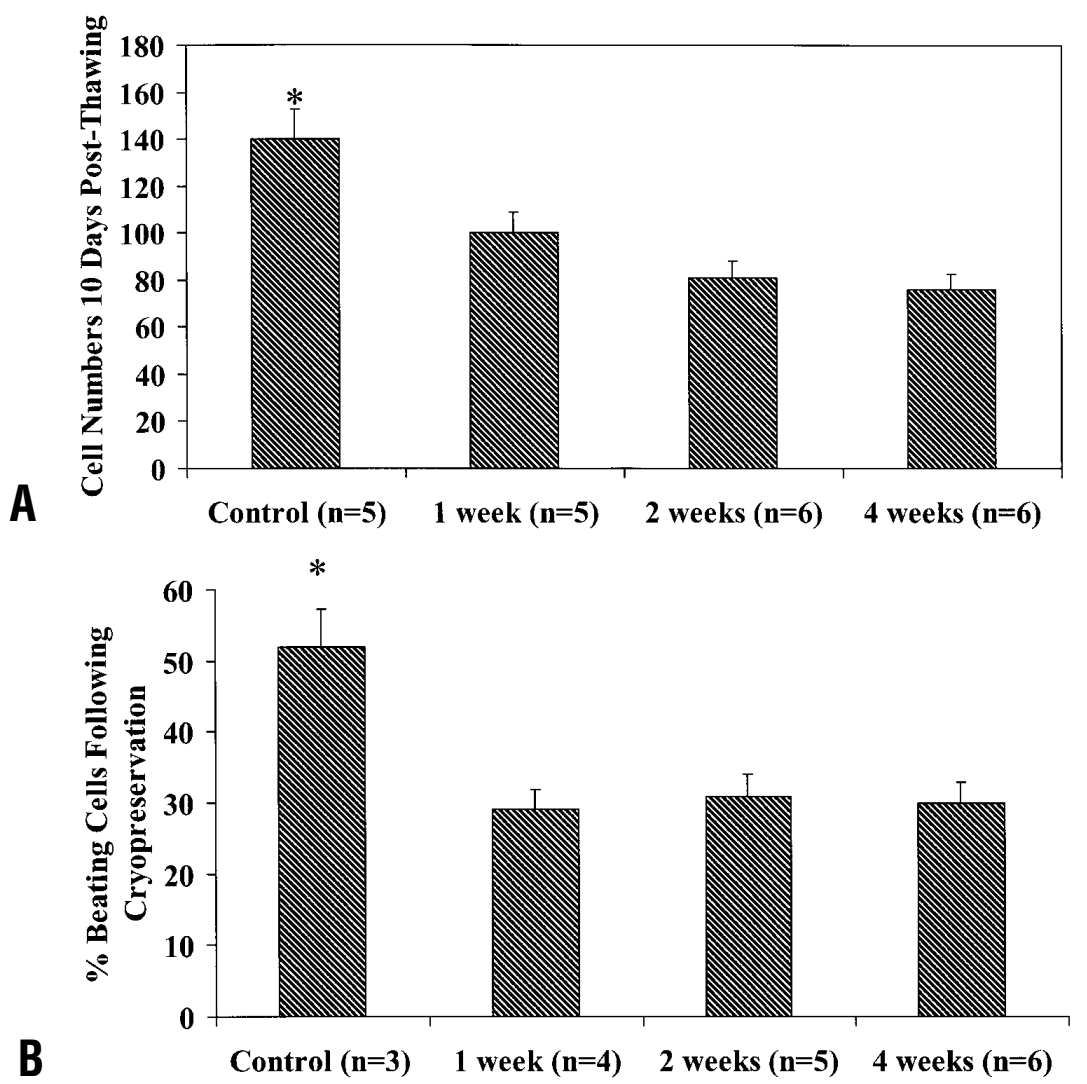

Fig 1. A, The effects of 1, 2, and 4 weeks of cryopreservation on cell number 10 days after thawing. The control group represents the noncryopreserved cells. Results are presented as mean $\pm \mathrm{SE}\left({ }^{*} P=.004\right.$, control different from 1-, 2-, and 4-week values). B, The effects of 1,2, and 4 weeks of cryopreservation on the percentage of beating cells 10 days after thawing. The control group represents the noncryopreserved cells. Results are presented as mean $\pm \mathrm{SE}\left({ }^{*} P=.01\right.$, control different from 1-, 2-, and 4-week values).

Cryopreservation represents an important and viable means of long-term storage of tissues and cells and has been widely used clinically. Cardiomyocyte cryopreservation, although previously not studied, represents a provocative area of research, which may serve to uncover novel means of restoring cardiac function in patients requiring a second transplantation of cells. In this study we describe, for the first time, the survival and contractile function of cryopreserved cardiomyocytes cultured from fetal rat myocardial tissue. In addition, we demonstrate the successful transplantation of cryopreserved cardiomyocytes into the subcutaneous tissue and myocardial scar tissue of Sprague-Dawley rats.

\section{Material and methods}

Animals. All procedures and protocols were approved by the Animal Care Committee of the University Health Network (Toronto, Ontario, Canada). Sprague-Dawley rats (Charles River Canada Inc, St Constant, Quebec, Canada) were used in the study. Fetal rat cardiomyocytes were freshly isolated from
18- to 20-day gestational age rat hearts. All experiments were performed in accordance with the "Guide for the Care and Use of Laboratory Animals" published by the National Academy Press, revised 1996).

Cell preparation. Fetal rat cardiomyocytes (18- to 20-day gestational age) were isolated by means of an enzymatic digestion method and cultured. In brief, pregnant rats were anesthetized with ketamine $(22 \mathrm{mg} / \mathrm{kg}$ body weight, intramuscularly) and pentobarbital (30 $\mathrm{mg} / \mathrm{kg}$ body weight, intraperitoneally). Fetal rat hearts were excised and then washed with phosphate-buffered saline (PBS) solution. After removal of all connective tissue, blood vessels, and the atria, the ventricles were minced and incubated in a PBS solution containing trypsin $(0.2 \%)$, collagenase $(0.1 \%)$, and glucose $(0.02 \%)$ for 30 minutes at $37^{\circ} \mathrm{C}$. The cardiac cells were then isolated by repetitive pipetting of digested myocardial tissue. The cells in the supernatant were transferred into a tube containing $15 \mathrm{~mL}$ of cell culture medium. The tube was centrifuged at $600 \mathrm{~g}$ for 5 minutes at room temperature.

Cell culture studies. The cell pellet was resuspended in culture medium. The cardiomyocytes were purified by a preplating method, ${ }^{4}$ which takes advantage of the finding that 


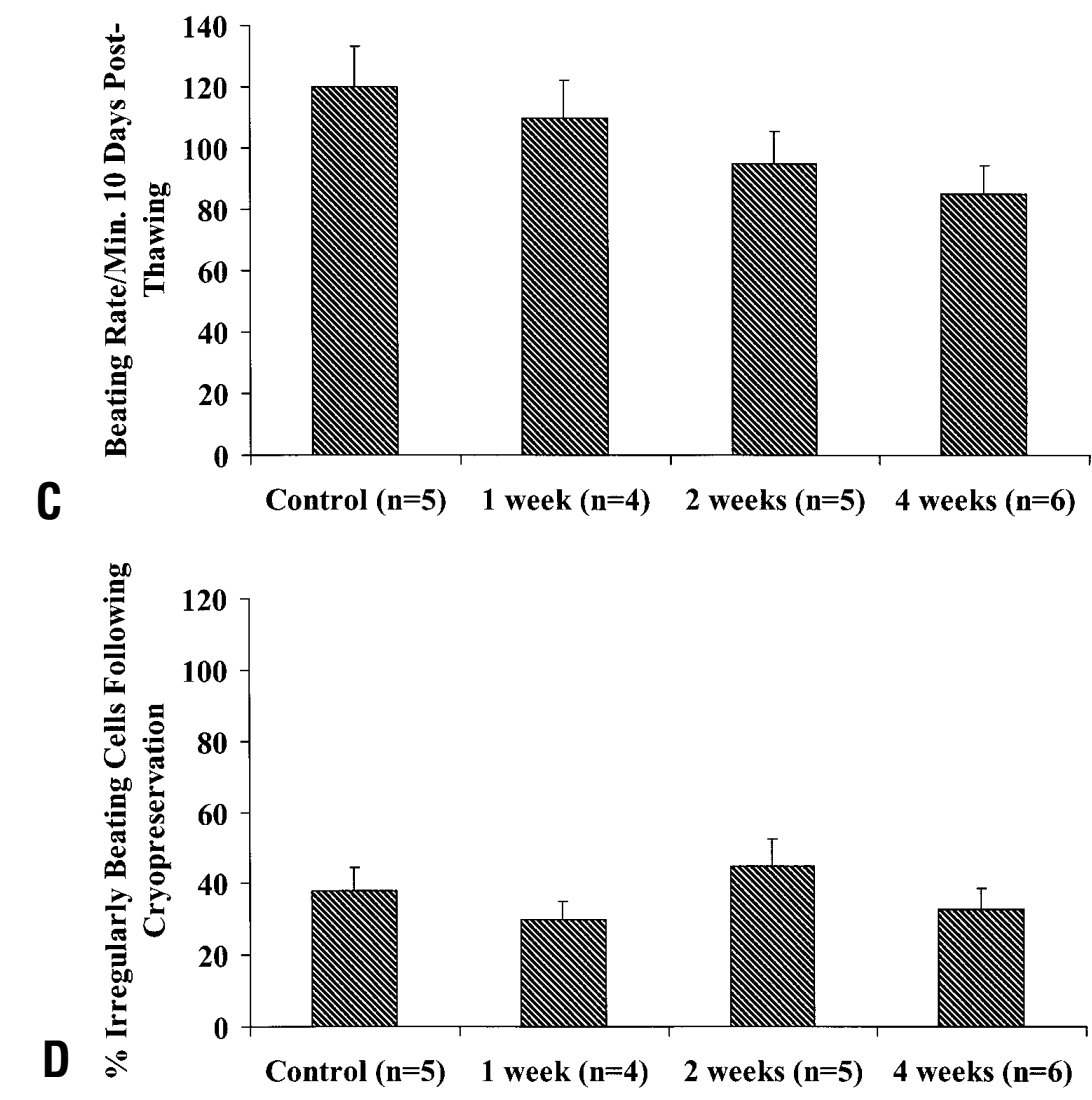

Fig 1. Cont'd. C, The effects of 1, 2, and 4 weeks of cryopreservation on the beating rate 10 days after thawing. The control group represents the noncryopreserved cells. Results are presented as mean \pm SE $(P>.05$, no difference between groups). D, The effects of 1,2 , and 4 weeks of cryopreservation on the percentage of irregularly beating cells 10 days after thawing. The control group represents the noncryopreserved cells. Results are presented as mean $\pm \mathrm{SE}(P>.05$, no difference between groups $)$.

cardiomyocytes require a longer time to attach to a cell culture dish than other cells in the myocardium (such as fibroblasts). The freshly isolated myocardial cells were plated on dishes and cultured for 2 hours at $37^{\circ} \mathrm{C}$. The supernatant containing the suspended cells was transferred into another dish for further culturing. The cardiomyocytes were cultured at $37^{\circ} \mathrm{C}$ in $5 \%$ carbon dioxide and $95 \%$ air as described earlier. ${ }^{2}$ For cryopreservation, fetal cardiomyocytes were transferred to cryogenic vials $(2.0 \mathrm{~mL}$ Nalgene cryovials; Applied Scientific, South San Francisco, Calif). They were resuspended in $2.0 \mathrm{~mL}$ of freezing medium (70\% Iscove's modified Dulbecco's medium and 20\% fetal bovine serum) and $10 \%$ dimethylsulfoxide (DMSO). The vials were placed into Nalgene cryovial freezing containers and cooled at a rate of $-1^{\circ} \mathrm{C}$ per minute until a temperature of $-80^{\circ} \mathrm{C}$ was reached (approximately 4 hours). The cryovials were then stored in liquid nitrogen. Control cells were not cryopreserved. After 1, 2 , and 4 weeks the cryopreserved samples were rapidly thawed in a $37^{\circ} \mathrm{C}$ water bath. Freezing medium was removed by dilution with culture medium after centrifugation for 5 minutes in 4 steps $(10 \%, 5 \%, 2.5 \%$, and 0\% DMSO) (approximately 30 minutes).
Tissue preservation. Cardiac tissues were separated into 3 groups on the basis of the minced size before cryopreservation. Groups 1, 2, and 3 were minced to less than $0.2 \mathrm{~mm}^{3}$, $2.0 \mathrm{~mm}^{3}$, and $6.0 \mathrm{~mm}^{3}$, respectively. The tissues were then cryopreserved by means of the method described above and stored in liquid nitrogen for 1 week. After cryopreservation, the tissues were thawed and the cells were isolated and cultured as described above.

\section{Cultured cell evaluation}

Proliferation. The proliferation of cryopreserved and noncryopreserved cells was determined by cell growth curves. The number of cells was determined daily for 10 days beginning on day 1 after thawing.

Rate of contraction. The rate of contraction, percentage of regular beating cells, and percentage of irregularly beating cells were examined for 10 days after thawing. The beating cardiomyocytes were observed in a $37^{\circ} \mathrm{C}$ heated chamber with a Nikon microscope (Nikon Corporation, Tokyo, Japan). The percentage of beating cells was determined by counting the number of beating cells (both regularly or irregularly beating cells) and the total number of cells in 5 random fields. 


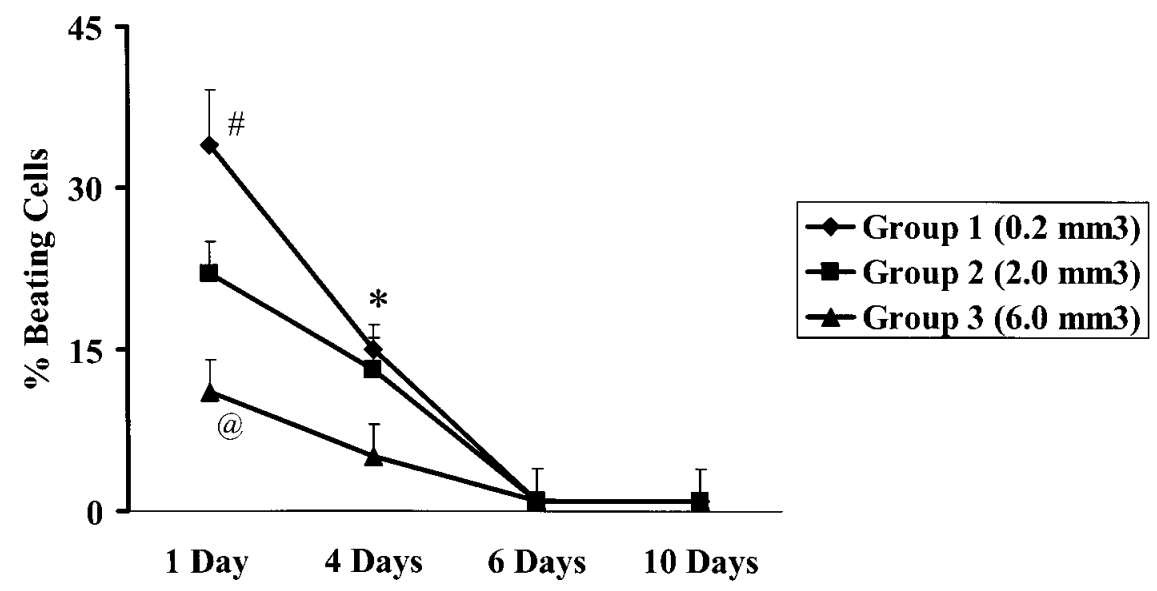

Fig 2. Effects of cryopreservation of fetal rat myocardial tissue on the percentage of cultured beating cardiomyocytes. Fetal rat myocardial tissue was minced to 3 sizes before cryopreservation $\left(0.2 \mathrm{~mm}^{3}, 2.0 \mathrm{~mm}^{3}\right.$, and $\left.6.0 \mathrm{~mm}^{3}\right)$ and cryopreserved for 1 week. After cryopreservation, cultured cardiomyocytes were isolated and cultured and the percentage of beating cells recorded in the 3 groups. Data are expressed as mean \pm SE. ${ }^{\#} P=.008$, different from groups 2 and $3 .{ }^{\circledR} P=.005$, different from groups 1 and $2 .{ }^{*} P=.005$, different from group 3 .

Transplantation studies. Cardiac cells were cryopreserved, thawed, and cultured as described above. The cultured cells were dissociated from the culture dishes with the trypsin solution and collected by centrifugation at $600 \mathrm{~g}$ for 5 minutes at room temperature. Once the cell number was determined, 4.2 $\pm 0.9 \times 10^{6}$ cells were resuspended in $1.0 \mathrm{~mL}$ of saline solution. A $0.25-\mathrm{mL}$ portion of the cell suspension was used for the subcutaneous implantation and $2.5 \times 10^{6}$ (suspended in $0.08 \mathrm{~mL}$ ) for the myocardial scar transplantation experiment.

Identification of transplanted cells in the myocardial scar. To identify the transplanted cells in the scar tissue, we labeled the cells with bromo-deoxyuridine (BrdU) (Sigma Chemical Company, St Louis, Mo $)^{5}$ before transplanting them. In brief, $10 \mu \mathrm{L}$ of BrdU solution (BrdU $50 \mathrm{mg}$, DMSO $0.8 \mathrm{~mL}$, and water $1.2 \mathrm{~mL}$ ) was added into each culture dish 1 day before the transplantation and incubated with the cells for 24 hours. Labeling efficiency was approximately $90 \%$. The labeled cells were transplanted into the 4-week-old transmural left ventricular scar, ${ }^{2}$ and samples were collected after 4 weeks of transplantation. Monoclonal antibodies against BrdU were used to localize the transplanted cardiomyocytes. After the paraffin had been removed with toluene, the samples were serially rehydrated with $100 \%, 95 \%$, and $70 \%$ ethanol. Endogenous peroxidase in the samples was blocked with $3 \% \mathrm{H}_{2} \mathrm{O}_{2}$ for 10 minutes (room temperature). The samples were treated with pepsin for 5 minutes at $42^{\circ} \mathrm{C}$ and $2 \mathrm{~N}$ $\mathrm{HCl}$ for 30 minutes (room temperature). After 3 rinses with PBS solution, the samples were incubated with antibodies against BrdU in a moist chamber for 16 hours (room temperature). A negative control sample was incubated in PBS solution (without the primary antibodies) under the same conditions. The test and control samples were rinsed with PBS solution 3 times (15 minutes each) and then incubated with goat anti-rabbit immunoglobulin $\mathrm{G}$ conjugated with peroxidase $\left(37^{\circ} \mathrm{C}\right.$ for 45 minutes). The samples were washed 3 times (15 minutes each) with PBS solution and then immersed in diaminobenzidine $\mathrm{H}_{2} \mathrm{O}_{2}$ solution $(2 \mathrm{mg} / \mathrm{mL}$ diaminobenzidine and $0.03 \% \mathrm{H}_{2} \mathrm{O}_{2}$ in $0.03 \mathrm{~mL} / \mathrm{L}$ phosphate buffer) for 15 minutes. After being washed with PBS solution, the samples were coverslipped and photographed.

\section{Cell transplantation}

Subcutaneous transplantation. All procedures were performed with the animals under general anesthesia (ketamine, $22 \mathrm{mg} / \mathrm{kg}$ body weight intramuscularly, and pentobarbital, $30 \mathrm{mg} / \mathrm{kg}$ body weight intraperitoneally). Once the animals were anesthetized, the superficial subcutaneous tissue of the quadriceps muscle was exposed through a 20$\mathrm{mm}$ skin incision, and the cell suspension of cryopreserved fetal cardiomyocytes ( $\mathrm{n}=5$ rats) was injected with a tuberculin syringe (see Fig 3, A). The skin incision was closed with 3-0 silk. The contralateral leg was injected with noncryopreserved cardiomyocytes $(n=5)$ and served as the control. The rats were housed in cages fitted with a filter and received cyclosporine A (INN: ciclosporin) at a dose of $5 \mathrm{mg} / \mathrm{kg}$ body weight per day (subcutaneously). Benzathine penicillin $\mathrm{G}, 37,500 \mathrm{U}$, and procaine penicillin $\mathrm{G}, 37,500$ $\mathrm{U}$, were administered intramuscularly every 3 days to each rat for 1 week after the operation. Buprenorphine $\mathrm{HCl}$ (0.01-0.05 $\mathrm{mg} / \mathrm{kg}$ body weight) was given subcutaneously every 8 to 12 hours for the first 2 days after the operation to provide analgesia. On day 28 after transplantation, the animals were anesthetized, the transplanted area was exposed, and contractile function of the transplanted cells was recorded. The electrical activity of the transplanted cells was recorded with electrocardiography (Patient Care Management System, model 90303B; Spacelabs Medical, 

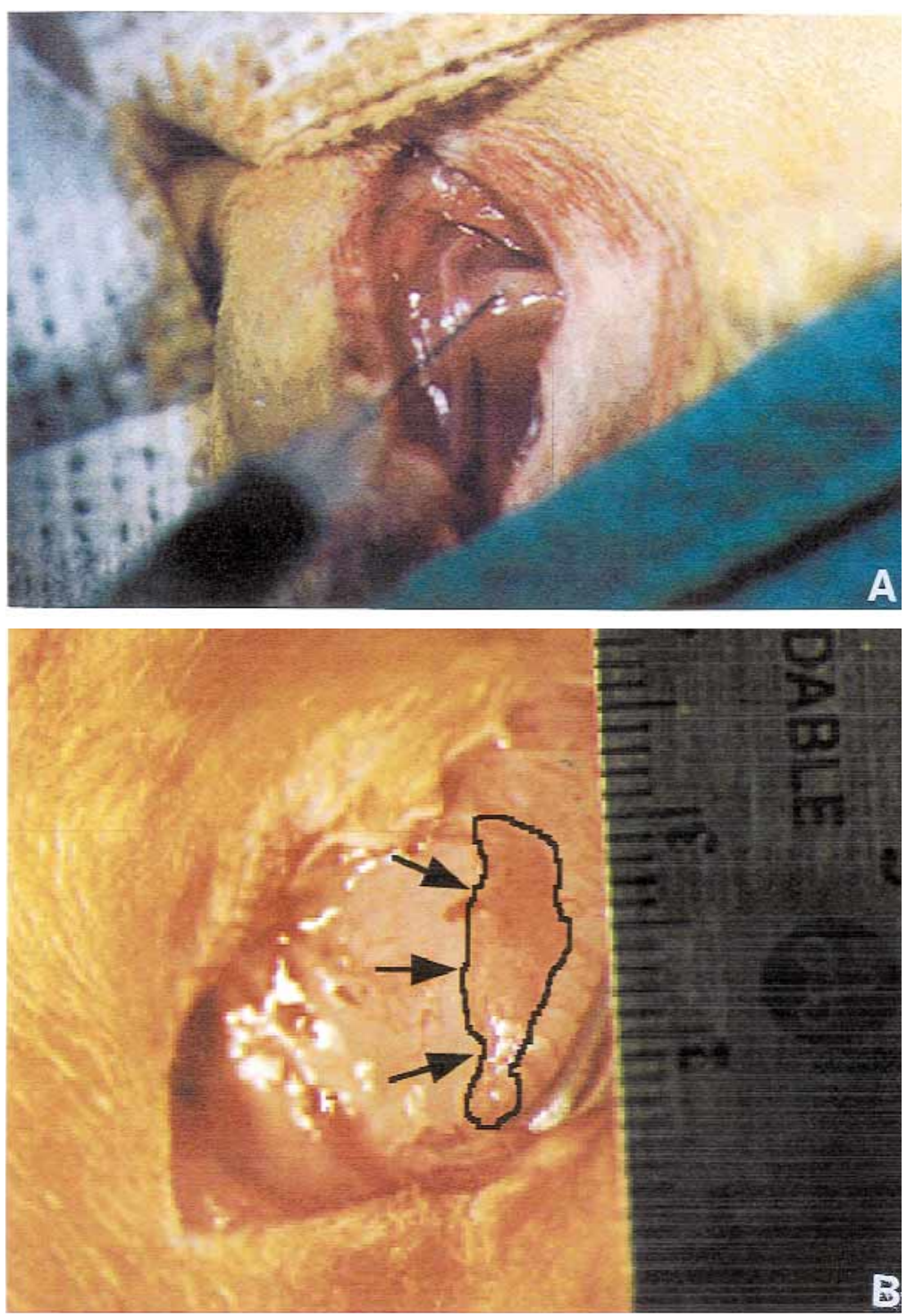

Fig 3. A, Fetal cardiomyocyte suspension being injected into the subcutaneous tissue of an adult rat hind limb. B, Contractile cardiomyocyte transplant (A) 4 weeks after the implantation. Successful transplantation into the subcutaneous tissue is depicted (dimensions: $14 \times 4 \mathrm{~mm}^{2}$ ).

Inc, Redmond, Wash) by placing a probe at each end of the transplanted tissue. The transplanted tissue was then collected for histologic studies.

Myocardial transplantation. In brief, the rats were anesthetized with ketamine followed by pentobarbital as described above. The anesthetized rats were intubated with a 14-gauge catheter and positive-pressure ventilation was maintained ( $3 \mathrm{~mL} /$ ventilation, 60 ventilations $/ \mathrm{min}$, room air supplemented with oxygen [flow rate $6 \mathrm{~L} / \mathrm{min}$ ]) using a Harvard ventilator (model 683; Harvard Apparatus Co, South Natick, Mass). The myocardium $(\mathrm{n}=5)$ was exposed through a 2-cm left lateral thoracotomy. The left ventricular free wall was then frozen with a $0.8 \times 1.2-\mathrm{cm}$ liquid nitrogen probe $(15$ applications of 20 seconds' duration each). The muscle layer and skin were closed with 5-0 sutures. The rats were monitored for 4 hours postoperatively. Benzathine penicillin G, $37,500 \mathrm{U}$ (intramuscularly), and procaine penicillin G, $37,500 \mathrm{U}$ (intramuscularly), were given to each rat every 3 days for 1 week after the operation. In addition, buprenorphine (0.01-0.05 $\mathrm{mg} / \mathrm{kg}$ body weight) was administrated subcutaneously every 8 to 12 hours for the first 48 hours after the operation for analgesia.

Four weeks after cryoinjury, the rat heart was exposed through a midline sternotomy with the rat under general anesthesia. ${ }^{2}$ The myocardial scar was exposed through a midline sternotomy. An $80-\mu \mathrm{L}$ aliquot of cardiomyocyte suspension 


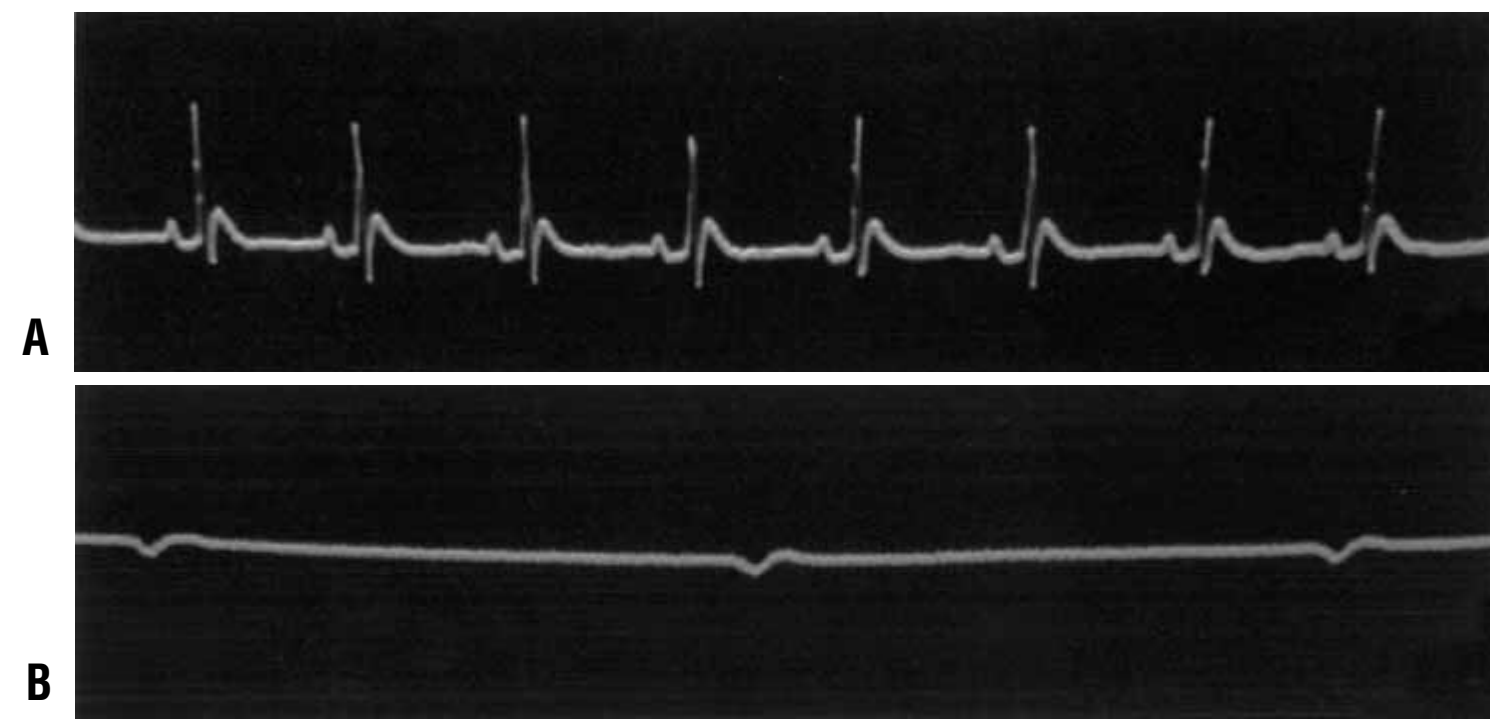

Fig 4. A, Electrocardiogram of the host rat heart. The heart rate was 219 beats/min. B, Electrical activity of the fetal cardiomyocyte transplant formed in the subcutaneous tissue of the adult rat hind limb 4 weeks after transplantation of cryopreserved fetal cardiomyocytes. The tissue beats at 60 beats/min with an idioventricular rhythm.

containing $2.5 \times 10^{6}$ cells was injected by means of a tuberculin syringe into the center of the left ventricular free wall scar tissue of each animal $(n=3)$ in the transplant group. An $80-\mu \mathrm{L}$ aliquot of Iscove's modified Dulbecco's medium was injected into the center of the scar tissue of the control hearts $(n=3)$. Cell and medium leakage from the site of injection was prevented by the application of cryoprecipitate. The chest was closed with 3-0 silk sutures. Antibiotics and analgesics were given as described above.

Histology. After 4 weeks of transplantation, subcutaneous and myocardial tissues were collected and fixed in 5\% glacial acetic acid (in methanol) for histologic studies ( $\mathrm{n}=6$ samples). The samples were embedded and sectioned to yield 10$\mu \mathrm{m}$ thick slices and stained with hematoxylin and eosin.

Statistical analysis. Results are presented as mean \pm SE. Statistical analysis was performed by repeated-measures analysis of variance with the use of the Number Cruncher Statistical System (NCSS Statistical Software, Kaysville, Utah) followed by a Newman-Keuls test for post hoc comparisons.

\section{Results}

Proliferation and rate of contraction of cultured fetal cardiomyocytes after cryopreservation. Fig $1, A$ and $B$, depicts the effects of cryopreservation of cultured fetal cardiomyocytes on cell number and percentage of beating cells at day 10 after thawing. Cryopreservation of fetal rat cardiomyocytes (for 1, 2, or 4 weeks) resulted in lower cell numbers when compared with the noncryopreserved control group (Fig 1, $A,{ }^{*} P=.004$ different from 1-, 2-, and 4-week values).
In addition, the percentage of beating cells was also diminished after 1,2 , and 4 weeks of cryopreservation (Fig $1, B,{ }^{*} P=.01$ different from 1-, 2-, and 4-week values). In contrast, the beating rates and percentage of irregularly beating cells were not affected by cryopreservation of fetal cardiomyocytes (Fig 1, $C$ and $D$, $P>.05)$.

Contractility of cardiomyocytes isolated from cryopreserved fetal myocardium. The contractile function of cardiomyocytes isolated from cryopreserved fetal rat myocardial tissue is depicted in Fig 2. As discussed earlier, segments of fetal rat myocardium were minced into 3 sizes $\left(0.2 \mathrm{~mm}^{3}, 2.0 \mathrm{~mm}^{3}\right.$, and 6.0 $\mathrm{mm}^{3}$ ) and cryopreserved for 1 week. After cryopreservation, the tissues were thawed, the cells isolated and cultured, and the percentage of beating cells was determined. The number of beating cells isolated in this fashion was a function of the size of the tissue; the lowest percentage of beating cells was recorded in the group with the largest mince size $\left(0.6 \mathrm{~mm}^{3}\right)$ (Fig 2). In contrast to the results obtained after cryopreservation of cultured fetal cardiomyocytes, the percentage of beating cells isolated from cryopreserved fetal myocardial tissue was significantly lower (average of groups 1 , 2 , and 3 on day $6[3 \% \pm 2 \%]$ vs percentage of beating cells following cryopreservation of cultured fetal cardiomyocytes on day 6 [28\% $\pm 3 \%$ ], $P=.0001$ ).

Transplantation experiments. Four weeks after subcutaneous transplantation of cryopreserved car- 

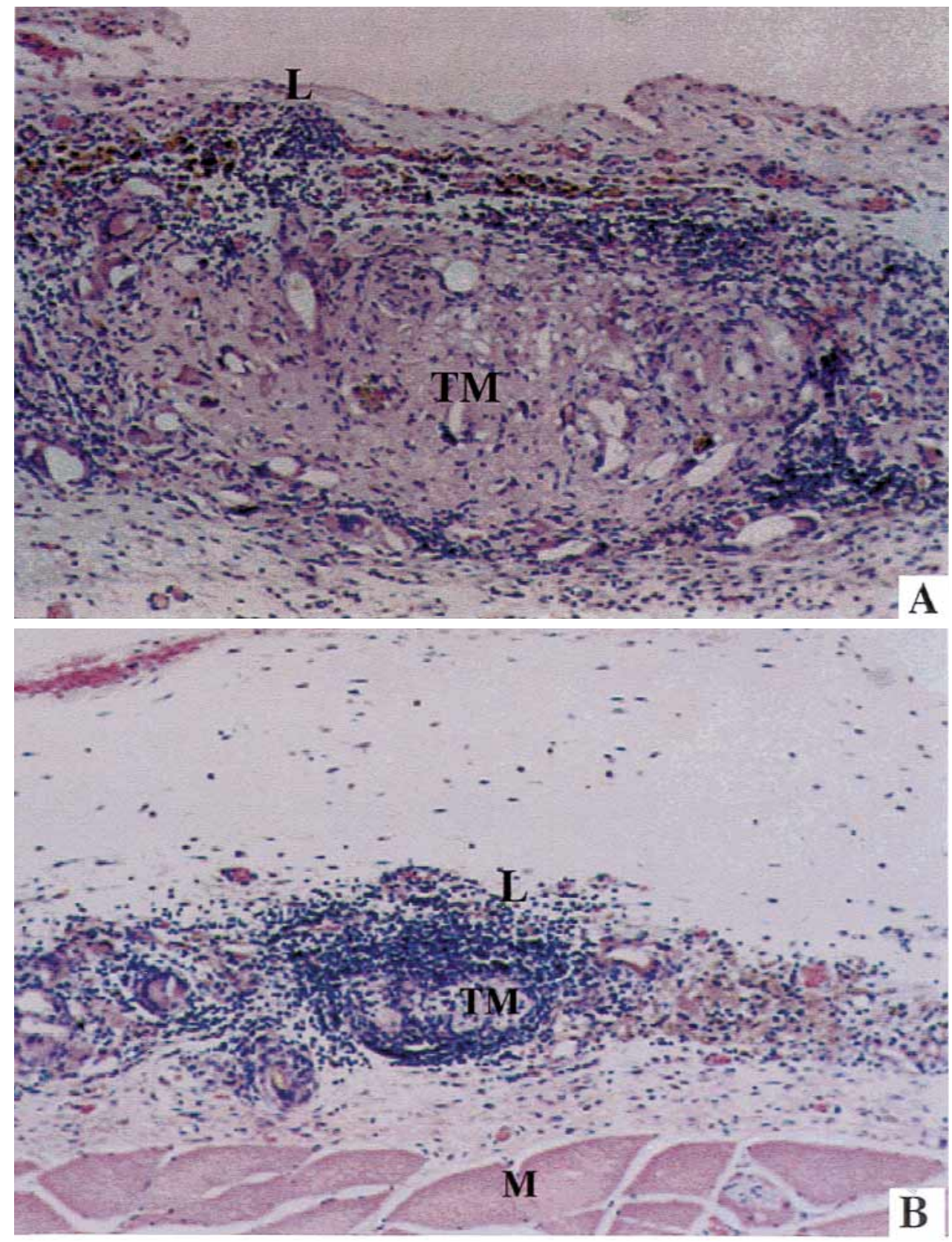

Fig 5. Hematoxylin and eosin photomicrograph $(100 \times)$ of fetal heart cell transplantation into the rat hind limb subcutaneous tissue. A, The 4-week-old transplant formed from a cryopreserved cardiomyocyte suspension. B, The 4week-old transplant formed from a noncryopreserved cardiomyocyte suspension. Evidence of immunologic rejection is present. $L$, lymphocytes; $T M$, transplant muscle; $M$, host muscle.

diomyocytes, a spontaneously contractile tissue of approximately $0.5 \mathrm{~cm}^{3}$ in size was apparent in the 2 transplantation sites of each animal (Fig 3,B). Four of 5 animals in the experimental group $(80 \%)$ and 3 of 5 animals in the control group $(60 \%)$ underwent success- ful transplantation. The experimental $(n=4)$ and control tissues $(n=3)$ beat spontaneously at rates of $60 \pm$ 9 and $34 \pm 2$ beats/min with an idioventricular rhythm (Fig 4, $A$ and $B$ ). The transplanted cells were elongated and formed myocardium-like tissue with blood vessels 


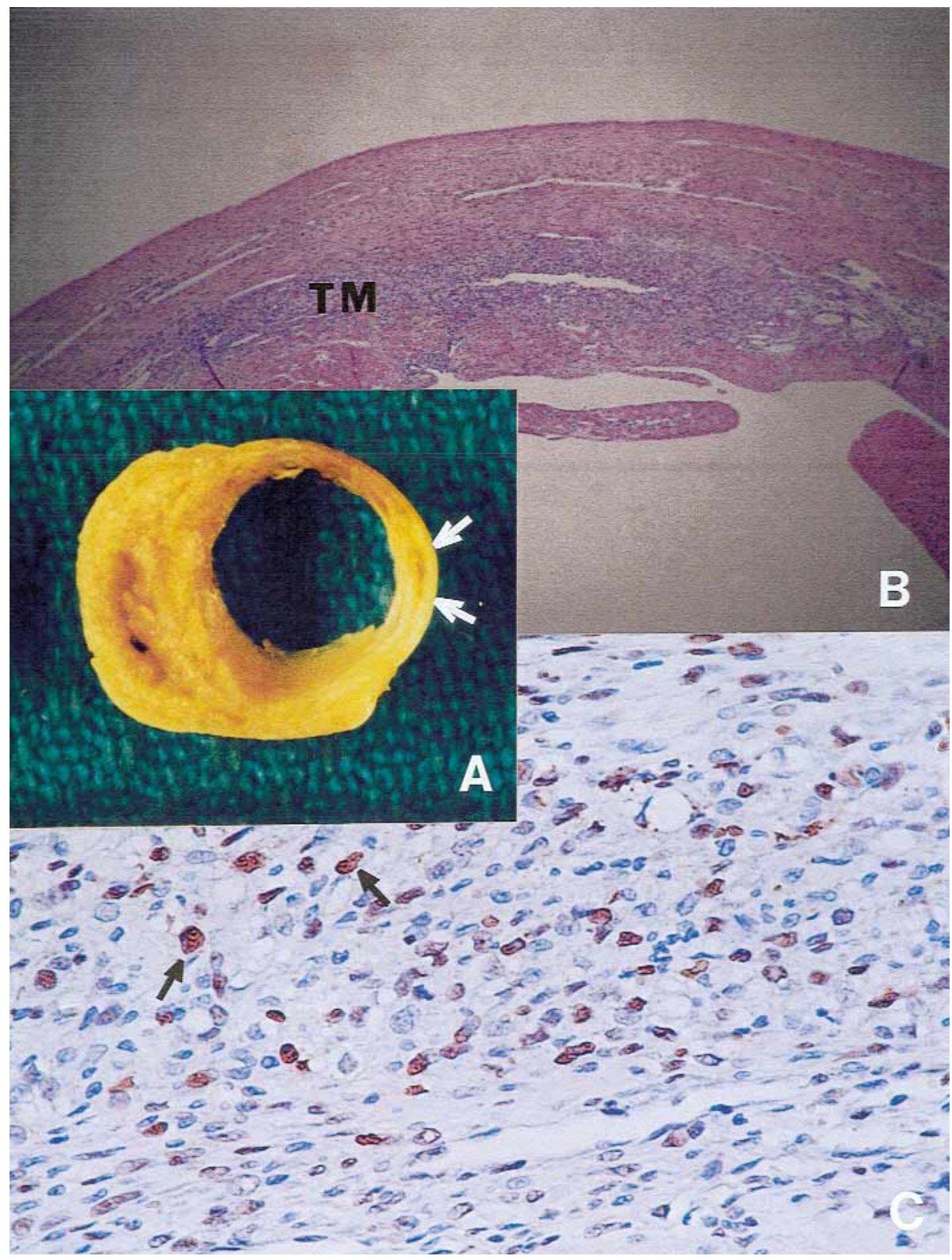

Fig 6. Photomicrographs of a 4-week-old fetal cardiomyocyte transplant in adult rat myocardial scar tissue. A, Arrows point to the transplant in the scar tissue of the left ventricular free wall. B, Hematoxylin and eosin stain of the transmural scar with transplant infiltrated with lymphocytes indicative of immunorejection (40×). C, Some cardiomyocytes labeled with BrdU were transplanted and identified in the transplant as indicated by the arrows (400×). TM, Transplant muscle.

present within the contractile tissue (Fig 5). After transplantation, BrdU-labeled myocardium-like tissue was observed in the center of the left ventricular free wall scar (Fig 6) only in the rats injected with fetal cardiomyocytes. A diffuse inflammatory reaction was present in the tissue (Fig 5). The tissue did not appear to be in contact with the host myocardium.

\section{Discussion}

Cryopreservation is a practical method for long-term storage of tissues and cells and has been successfully used in storing cardiac valves, blood vessels, and bone marrow cells. ${ }^{6-8}$ The effects of cryopreservation on survival and function of cultured cardiomyocytes has not been previously described. In this article, we address 
this issue and demonstrate for the first time that cryopreserved fetal cardiomyocytes are both viable and functional and can be successfully transplanted into subcutaneous and myocardial scar tissue.

With respect to the data presented in this article, a few issues merit brief discussion. Fetal rat cardiomyocytes retained myocardium-like characteristics in culture after cryopreservation. With long storage times, the cell numbers and percentage of beating cells were diminished at day 10 after thawing. In addition, cell passage decreased the survival and rate of contraction to an equal degree in both groups (not shown). These data raise an important technical issue regarding the rate of survival of cultured fetal cardiomyocytes after cryopreservation. Despite the use of standard cryopreservation techniques, rapid thawing, and effective culture methodology, cryopreservation of freshly prepared cardiomyocytes was associated with high rates of cell loss. Clearly, improving and refining cryopreservation techniques may be needed to augment cardiomyocyte yield and function.

Cryoprotectants have been demonstrated to affect the secondary protein structure through changes in water structure and/or by a direct interaction between the cryoprotectant and the protein. ${ }^{9}$ Gottsauner-Wolf and associates ${ }^{10}$ have previously demonstrated that freezing and subsequent thawing significantly decrease the tensile properties of normal skeletal muscle. Furthermore, the method of removing DMSO was an important determinant of cell survival, with cell injury apparent when the DMSO was removed by diluting it with culture medium at $37^{\circ} \mathrm{C}$. Studies of thermal expansion at varying concentrations of DMSO may be useful in improving the cell survival after cryopreservation.

The number of contractile cardiomyocytes isolated from cryopreserved fetal myocardial tissue was a function of mince size before cryopreservation; the lowest percentage of beating cells was obtained in the tissues with the largest mince size $\left(6.0 \mathrm{~mm}^{3} \mathrm{vs} 0.2 \mathrm{~mm}^{3}\right)$. This may reflect a relative inability of DMSO to diffuse into myocardial cells with larger tissue/mince size. In addition, the percentage of beating cardiomyocytes cultured from cryopreserved fetal myocardial tissue was lower than that observed after cryopreservation of freshly cultured cardiomyocytes. Although we are unable to provide an explanation for this finding, it is plausible that cryopreservation of myocardial tissue favored survival of noncardiomyocyte cells and/or nonfunctional cardiomyocytes after culture. Research efforts in this direction are required to shed light on this issue.

The present study also describes the successful transplantation of cryopreserved fetal cardiomyocytes into subcutaneous tissue and myocardial scar tissue of Sprague-Dawley rats. In the subcutaneous tissue, spontaneously beating myocardium-like tissue was formed 4 weeks after the transplantation of cryopreserved fetal cardiomyocytes. The beating rate of the myocardial scar tissue transplant could not be ascertained because of the background beating rate of the host myocardium. Despite the use of cyclosporine, the subcutaneous and myocardial transplants were infiltrated with lymphocytes, indicating the presence of various degrees of immunorejection.

\section{Limitations and perspective}

We would like to briefly address some of the limitations of the present study in an effort to encourage future studies in this area. Our primary purpose was to evaluate the viability and percentage of beating cells of cryopreserved fetal cardiomyocytes and cardiomyocytes isolated from cryopreserved fetal myocardial tissues. There are significant differences in fetal versus adult cardiomyocytes, which should be kept in mind while interpreting the data. Since the use of cyclosporine (in our study) makes the applicability of homologous myocytes uncertain, studies using genetically identical rats are needed to eliminate this factor.

In summary, freshly cultured fetal cryopreserved cardiomyocytes and cardiomyocytes cultured from cryopreserved fetal myocardial tissue are viable and functional. Furthermore, transplantation of cryopreserved fetal cardiomyocytes forms myocardium-like tissue in the rat subcutaneous tissue and left ventricular free wall scar. Further refinements of the cryopreservation techniques are needed to augment the rates of cardiomyocyte survival and improve the percentage of beating cardiomyocytes reported in this article.

\section{REFERENCES}

1. Taylor DA, Atkins BZ, Hungspreugs P, Jones TR, Reedy MC, Hutcheson KA, et al. Regenerating functional myocardium: improved performance after skeletal myoblast transplantation. Nature Med 1998;4:929-33.

2. Li R-K, Jia Z-Q, Weisel RD, Mickle DAG, Zhang J, Mohabeer $\mathrm{MK}$, et al. Cardiomyocyte transplantation improves heart function. Ann Thorac Surg 1996;62:654-61.

3. Sakai T, Li R-K, Weisel RD, Mickle DAG, Kim E-J, Tomita S, et al. Autologous heart cell transplantation improves cardiac function after myocardial injury. Ann Thorac Surg 1999;68:2074-81.

4. Simpson P, McGrath A, Savion S. Myocyte hypertrophy in neonatal rat heart cultures and its regulation by serum and by catecholamines. Circ Res 1982;51:787-801.

5. Magaud JP, Sargent I, Clarke PJ, Ffrench M, Rimokh R, Mason DY. Double immunohistochemical labeling of cell and tissue 
samples with monoclonal anti-bromodeoxyuridine. J Histochem Cytochem 1989;37:1517-27.

6. O'Brien MF, Stafford EG, Gardner MAH, Pohlner PG, Tesar PJ, Cochrane AD, et al. Allograft aortic valve replacement: long-term follow up. Ann Thorac Surg 1995;60(2Suppl):S65-70.

7. Muller-Schweinitzer E, Stulz P, Striffeler H, Haefeli WE. Functional activity and transmembrane signaling mechanisms after cryopreservation of human internal mammary arteries. J Vasc Surg 1998;27:528-37.

8. Deschamps C, Trastek VF, Ferguson JL, Martin WJ, Colby TV,
Pairolero PC, et al. Cryopreservation of canine trachea: functional and histological changes. Ann Thorac Surg 1989;47:208-12.

9. Huang P, Dong A, Caughey WS. Effects of dimethyl sulfoxide, glycerol, and ethylene glycol on the secondary structures of cytochrome $\mathrm{c}$ and lysozyme as observed by infrared spectroscopy. J Pharm Sci 1995;84:387-95.

10. Gottsauner-Wolf F, Grabowski FF, Chao EY, An KN. Effects of freeze/thaw conditioning on the tensile properties and failure mode of bone-muscle units: a biochemical and histological study in dogs. J Orthop Res 1995;13:90-5. 